Resectron

\title{
Different modes of GH administration influence gene expression in the male rat brain
}

\author{
Marion Walser ${ }^{1}$, Linus Schiöler ${ }^{2}$, Jan Oscarsson ${ }^{3}$, Maria A I Åberg ${ }^{4,5}$, Johan Svensson ${ }^{1}$, \\ N David Åberg ${ }^{1,5, *}$ and Jörgen Isgaard ${ }^{1, *}$ \\ 'Laboratory of Experimental Endocrinology, Department of Internal Medicine, The Sahlgrenska Academy, \\ Sahlgrenska University Hospital, University of Gothenburg, Blå Stråket 5, SE-413 45 Gothenburg, Sweden \\ ${ }^{2}$ Department for Public Health and Community Medicine, The Sahlgrenska Academy, University of Gothenburg, \\ Gothenburg, Sweden \\ ${ }^{3}$ AstraZeneca R\&D, SE-431 83 Mölndal, Gothenburg, Sweden \\ ${ }^{4}$ Institute for Neuroscience and Physiology, The Sahlgrenska Academy, Center for Brain Repair and Rehabilitation \\ and ${ }^{5}$ Department of Primary Health Care, Institute of Medicine, The Sahlgrenska Academy, University of \\ Gothenburg, Gothenburg, Sweden \\ (N D Åberg and J Isgaard contributed equally with respect to senior position)
}

Correspondence should be addressed to N D Åberg Email david.aberg@medic.gu.se

\begin{abstract}
The endogenous secretion pattern in males of $\mathrm{GH}$ is episodic in rats and in humans, whereas $\mathrm{GH}$ administration is usually even. Different types of $\mathrm{GH}$ administration have different effects on body mass, longitudinal bone growth, and liver metabolism in rodents, whereas possible effects on brain plasticity have not been investigated. In this study, GH was administered as a continuous infusion or as two daily injections in hypophysectomized male rats. Thirteen transcripts previously known to respond to $\mathrm{GH}$ in the hippocampus and parietal cortex (cortex) were assessed by RT-PCR. To investigate the effects of type of GH administration on several transcripts with different variations, and categories of transcripts (neuron-, glia-, and GH-related), a mixed model analysis was applied. Accordingly, GH injections increased overall transcript abundance more than $\mathrm{GH}$ infusions ( $21 \%$ in the hippocampus, $P<0.001$ and $10 \%$ in the cortex, $P=0.09$ ). Specifically, GH infusions and injections robustly increased neuronal hemoglobin beta $(\mathrm{Hbb}$ ) expression significantly (1.8- to 3.6-fold), and $\mathrm{GH}$ injections were more effective than $\mathrm{GH}$ infusions in increasing $\mathrm{Hbb}$ in the cortex $(41 \%, P=0.02)$, whereas a $23 \%$ difference in the hippocampus was not significant. Also cortical connexin 43 was higher in the group with $\mathrm{GH}$ injections than in those with $\mathrm{GH}$ infusions $(26 \%, P<0.007)$. Also, there were differences between GH injections and infusions in GH-related transcripts of the cortex $(23 \%, P=0.04)$ and glia-related transcripts of the hippocampus $(15 \%, P=0.02)$. Thus, with the exception of $H b b$ there is a moderate difference in responsiveness to different modes of $\mathrm{GH}$ administration.
\end{abstract}
Key Words
- growth hormone
type of administration
- transcript
- CNS
- quantitative PCR
- mixed model analysis (male, brain)

Journal of Endocrinology (2014) 222, 181-190

\section{Introduction}

Both animal and human studies show that growth hormone (GH) improves cognition. For instance, it is known that GH administration improves memory parameters in rats (Schneider-Rivas et al. 1995, Le Greves et al. 2006). In accordance, lack of GH, as in severe GH deficiency in adult humans with hypopituitary, is 
Table 1 Gene names and abbreviations of commercially available probes. The probes are assay-on-demand mixes of primers and TaqMan MGB probes (FAM dye labeled). Further details can be obtained at http://www.appliedbiosystems.com

\begin{tabular}{l} 
Gene symbol \\
\hline Transcript data \\
Ghr \\
Igf1 \\
Igf1r \\
Esr1 \\
Cnp \\
Gja1 \\
Gfap \\
Grin2a \\
Dlg4 \\
Gabbr1 \\
Gria1 \\
Oprd1 \\
Hbb-b1 \\
Gapdh
\end{tabular}

Fullname

Alias or

abbreviation in Ms

Growth hormone receptor Insulin-like growth factor 1 Insulin-like growth factor 1 receptor Estrogen receptor 1

$2^{\prime}, 3^{\prime}$-Cyclic nucleotide $3^{\prime}$ phosphodiesterase Gap junction alpha-1 protein (connexin 43) Glial fibrillary acidic protein Glutamate receptor, ionotropic,

2a ( $N$-methyl D-aspartate receptor 2a)

Discs, large (Drosophila) homolog-associated protein 4/postsynaptic density-95 Gamma-aminobutyric acid $\beta$ receptor 1 Glutamate receptor, ionotropic, AMPA1 Opioid receptor, delta 1 Hemoglobin, beta adult major chain Glyceraldehyde 3-phosphate dehydrogenase
Ghr

Igf1

Igflr

Esr1

Cnp

Gja1 (Cx43)

Gfap

Grin2a (Nr2a/Nmda2a)

Psd95

Gabbr1 (Gabab1)

Grial

Oprd1 (Dor)

$\mathrm{Hbb}$

Gapdh
Assay number

$\mathrm{Rn} 00567298 \mathrm{~m} 1$ Rn 99999087_m1 $\mathrm{Rn} 00583837 \mathrm{~m} 1$ $\mathrm{Rn} 01640372 \_\mathrm{m} 1$ $\mathrm{Rn}$ 01399463_m1 $\mathrm{Rn}$ 01433597_m1 Rn 00566603_m1 Rn 00561341_m1

Rn 00571479 m1

$\mathrm{Rn} 02586477 \mathrm{~m} 1$ $\mathrm{Rn}$ 00709588_m1 $\mathrm{Rn}$ 00561699_m1 Rn 00583657_g1 Rn 01462662_g1 associated with an impaired quality of life including fatigue and poor memory (McGauley 1989, Bengtsson et al. 1993, Falleti et al. 2006, Åberg et al. 2010), and these symptoms are remedied by $\mathrm{GH}$ replacement therapy (McGauley 1989, Bengtsson et al. 1993, Falleti et al. 2006, Åberg et al. 2010). A number of biochemical counterparts and mediators of these functional effects, including plasticity-related effects on synaptic proteins, astrocytes, and neurons, have been described (Tables 1 and 2). Importantly, GH administration also exerts neuroprotective (Gustafson et al. 1999, Scheepens et al. 2001, Pathipati et al. 2009) and cell-proliferative effects
(Åberg et al. 2009, 2010). The fact that GH-receptors are expressed in both glial cells and neurons (Lobie et al. 1993) and that GH crosses the blood-brain barrier (BBB) (Lopez-Fernandez et al. 1996, Ye et al. 1997) indicates that circulating GH can stimulate both cell types directly.

In rodents, $\mathrm{GH}$ secretion occurs in regular large bursts with periods of no $\mathrm{GH}$ secretion which are called troughs. This pattern is typical of male rats, as compared with the female pattern of secretion which is considerably more even (Eden 1979). Also, a pulsatile mode of GH administration has been suggested to mimic the male pattern of endogenous GH secretion (Jansson et al. 1982). In male

Table 2 Key references and main function for the transcripts that are predominantly expressed in neuronal or glial cells. Supplementary Table 1 has an extended detailed table regarding the exact effects of GH described previously

\begin{tabular}{|c|c|}
\hline Abbreviation & Primarily in cell type \\
\hline Ghr & Neuron/glia \\
\hline $\lg f 1$ & Neuron/glia \\
\hline lgf1r & Neuron/glia \\
\hline Esr1 & Neuron/glia \\
\hline Grin2a & Neuron \\
\hline Psd95 & Neuron \\
\hline$H b b$ & Neuron \\
\hline Gabbr1 & Neuron \\
\hline Gria 1 & Neuron \\
\hline Oprd1 & Neuron (glia) \\
\hline Cnp & Glia \\
\hline Gjal & Glia \\
\hline Gfap & Glia \\
\hline
\end{tabular}

Main function
Brain plasticity
Brain plasticity
Brain plasticity
Brain plasticity
Hippocampal synaptic plasticity
Hippocampal synaptic plasticity
O$_{2}$-regulatory protein
Inhibitory neurotransmitter/
neuroprotection
Excitatory neurotransmitter receptors
Neuroprotective effects
Formation of the myelin sheath
Cell communication
Excitatory neurotransmitter/morphogenesis

\section{Reference(s)}

Le Greves et al. (2002)

Lopez-Fernandez et al. (1996), Ye (1997) and Adams et al. (2009)

Le Greves et al. (2006)

Pons \& Torres-Aleman (1993)

Le Greves et al. (2002) and Le Greves et al. (2006)

Le Greves et al. (2006)

Ohyagi et al. (1994), He et al. (2009) and Walser et al. (2011)

Chebib \& Johnston (1999), Bettler et al. (2004) and Xu et al. (2008)

Craig et al. (1993) and Martin et al. (1993)

Persson et al. (2003) and Iwata et al. (2007)

Ảberg et al. (2007)

Åberg et al. (2000)

Pekny et al. (1995) 
rats, it has been shown that pulsatile GH treatment enhances mRNA levels of insulin-like growth factor 1 (Igf1) more than GH infusions in the rib growth plate, skeletal muscle (Isgaard et al. 1988), and liver (Maiter et al. 1992). However, with respect to effects on the brain, the influence of the type of GH administration, to our knowledge, has not been investigated.

GH and IGF1 have many similar effects in the brain. For example, in rodents, both GH (Gustafson et al. 1999, Scheepens et al. 2001, Pathipati et al. 2009) and IGF1 (Guan et al. 2001, 2003, Lin et al. 2005, Kooijman et al. 2009) have been shown to protect the brain against hypoxic-ischemic (HI) injuries. Circulating IGF1 is believed to mediate some of the effects of GH on the brain (for review, see Åberg et al. (2006)). This is possible as IGF1 crosses the BBB via carrier-mediated uptake (Armstrong et al. 2000). In addition, both IGF1 (D'Ercole et al. 1996, Folli et al. 1996) and IGF1R (Yan et al. 2011) are expressed in brain. Therefore, when investigating the effects of GH administration on the brain it is of interest to measure the components of the local GH-IGF1 system.

Our hypothesis was that different modes of administration of GH would elicit different responses in previously known plasticity-related targets of GH therapy. We selected two important brain regions, namely the hippocampus and parietal cortex (henceforth cortex), where most previous effects of GH have been reported (Tables 1 and 2 and Supplementary Table 1, see section on supplementary data given at the end of this article). In order to investigate the mode of $\mathrm{GH}$ administration, we administered bovine $\mathrm{GH}$ (bGH) as twice daily injections or as a continuous infusion through osmotic minipumps in hypophysectomized ( $\mathrm{Hx})$ male rats with basal replacement of cortisol and thyroxine $\left(\mathrm{T}_{4}\right)$. The paradigms were chosen because GH administered twice daily caused a better growth response than GH administered as a continuous infusion (Jansson et al. 1982, Isgaard et al. 1988).

The transcripts were divided into three categories (see Tables 1 and 2 for references and Supplementary Table 1 for details on previous regulation). The first category was the GH-related transcripts, in which Ghr, Igf1, Igf1r, and the estrogen receptor 1 alpha receptor (Esr1) were included, as estradiol has been shown to interact with the IGF1R (Pons \& Torres-Aleman 1993). In the neuronrelated category, we included six transcripts: neuronhemoglobin beta ( $\mathrm{Hbb}$; presented separately), postsynaptic density-95 (Psd95), and gamma-aminobutyric acid B receptor (Gabab1 (Gabbr1)), as their expression is increased by GH. In addition, the glutamate AMPA receptor (Gria1) and neuronal glutamate receptor $\mathrm{N}$-methyl D-aspartate receptor 2a (Nr2a (Grin2a)) were added, as the synaptic plasticity of the hippocampus is enhanced by chronic GH treatment. Not all effects of GH are increments, specifically the delta opioid receptor (Dor (Oprd1)) abundance is decreased by GH. In the glia-related category, we included three transcripts. The gap junction alpha-1 protein (Cx43 (Gja1)) and the glial fibrillary acidic protein (Gfap) were selected as they are increased by GH. Also, as Little mice (mono-deficient in GH) exhibit reduced markers of myelination, we chose to study myelination as indexed by cyclic nucleotide phosphodiesterase (Cnp).

\section{Materials and methods}

\section{Animals and hormonal treatment}

Male $(n=20)$ Sprague-Dawley rats (Møllegaard Breeding Center Ltd, Ejby, Denmark) were maintained under standard conditions of temperature $\left(24-26^{\circ} \mathrm{C}\right)$ and humidity (50-60\%) and with lights on between 0500 and $1900 \mathrm{~h}$ each day. The rats had free access to standard laboratory chow and water (Rat and mouse standard diet, B\&K Universal Limited, Sollentuna, Sweden). Normal pituitary-intact rats (henceforth intact) and $\mathrm{Hx}$ rats were kept to monitor effects of hypophysectomy per se, and to evaluate whether the administration of bGH restored specific transcript expression to relevant physiological levels.

The effects of hormonal administration were evaluated in rats, which were hypophysectomized $(\mathrm{Hx})$ at 50 days of age ( $n=5-6$ in each group). Hormone administration was initiated 7 days after hypophysectomy and maintained for 7 days. All $\mathrm{Hx}$ rats received substitution therapy with cortisol phosphate $(\mathrm{C} ; 400 \mu \mathrm{g} / \mathrm{kg}$ per day; Solucortef, Upjohn, Puurs, Belgium) and $\mathrm{L}-\mathrm{T}_{4}(10 \mu \mathrm{g} / \mathrm{kg}$ per day; Nycomed, Oslo, Norway), which were diluted in saline and administered subcutaneously once daily at $0800 \mathrm{~h}$ (Thorngren \& Hansson 1973, Jansson et al. 1982). These rats were randomly divided into a control group (henceforth $\mathrm{Hx}$ in all figures) and two GH treatment groups, which received bGH. Recombinant bGH, donated from American Cyanamide Co. (Princeton, NJ, USA), was diluted in a $0.05 \mathrm{M}$ phosphate buffer of $\mathrm{pH} 8.6$ with $1.6 \%$ glycerol and $0.02 \%$ sodium azide and administered as a s.c. infusion $(0.7 \mathrm{mg} / \mathrm{kg}$ per day) for 7 days through miniosmotic pumps (model 2004, Alzet, Cupertino, CA, USA) implanted subcutaneously in the neck (henceforth GHi) or as injections (henceforth GHx2, i.e. $0.35 \mathrm{mg} / \mathrm{kg}$, twice

Published by Bioscientifica Ltd. 
Table 3 Weight gains of experimental animals treated with bGH for 7 days. Two-tailed $t$-tests are performed relative to $\mathrm{Hx}$. Variation is given as $95 \% \mathrm{Cls}$

\begin{tabular}{lrrr}
\hline & Weight gain & \multicolumn{1}{c}{} \\
\cline { 1 - 1 } Intact & $58.5 \pm 1.7$ & & $<0.001$ \\
$\mathrm{hx}$ & $-4.4 \pm 1.7$ & & \\
$\mathrm{hx}+\mathrm{GHi}$ & $25.4 \pm 1.5$ & & $<0.001$ \\
$\mathrm{hx}+\mathrm{GHx} 2$ & $30.9 \pm 2.5$ & $<0.001$
\end{tabular}

daily, equaling a total of $0.7 \mathrm{mg} / \mathrm{kg}$ per $24 \mathrm{~h}$ ) (Oscarsson et al. 1999). All animals were weighed every 2 or 3 days to monitor the biological response in weight gain (Table 3 ). After decapitation, the brain tissue was dissected and immediately frozen in liquid nitrogen and stored at $80^{\circ} \mathrm{C}$. All treatment procedures were approved by the Board of Animal Ethics of Göteborg University.

\section{RT-PCR}

Transcripts were analyzed by quantitative RT-PCR (qPCR). Total RNA was extracted from the hippocampus and cortex using the Tri Reagent solution (Ambion, Carlsbad, CA, USA). cDNA was prepared from 250 ng total RNA, using conditions recommended by the supplier (HighCapacity cDNA RT Kit, Applied Biosystems). RNA quality was high as verified by spectrophotometric analysis of absorption at 260 vs $280 \mathrm{~nm}$ u.v. light (not shown). The qPCR analysis was carried out using an ABI Prism 7900 Sequence Detection System (Applied Biosystems). Predesigned, TaqMan Gene Expression Assays were used to detect each gene (Applied Biosystems, Table 1). The amount of each transcript was normalized to the amount of Gapdh expressed in the same sample. For stability comparison of candidate reference genes, we applied the NormFinder Software (http://www.mdl.dk; Andersen et al. 2004, Bonefeld et al. 2008). All samples were analyzed in duplicates. The relative comparative $C_{\mathrm{T}}$ method was used to analyze the qPCR data (Sequence Detector User Bulletin \#2, Applied Biosystems), where $C$ stands for the number of cycles required to detect the transcript at a defined luminescence. In the $C_{\mathrm{T}}$ method, the amount of target normalized to an endogenous reference and relative to a calibrator sample is given by: $2^{-\Delta \Delta C_{\mathrm{T}}}$, where $\Delta C_{\mathrm{T}}$ is the $C_{\mathrm{T}}$ for the sample minus $C_{\mathrm{T}}$ for Gapdh of the same sample and $\Delta \Delta C_{\mathrm{T}}$ is the $\Delta C_{\mathrm{T}}$ minus the $\Delta C_{\mathrm{T}}$ for the calibrator. The presented values in the paper are thus delogarithmized and represent arbitrary but linear relative amounts of each transcript. The calibrator is the same defined stock sample analyzed in triplicates in each of the quantitative qPCRs.

\section{Statistical analysis}

Variation was expressed as $95 \%$ CI for each group. Comparisons between any two groups were made with two-tailed $t$-test, listed in Table 2 . Each group value was normalized to that for the intact group $=100$.

For all other statistical comparisons, a mixed model was used to evaluate the general effects of GHi and GHx2 and effects related to each of the categories of transcripts. Mixed models allow the study of both fixed effects (as in the example usual ANOVA) and random effects. Rat was used as a random effect to account for the within-rat correlation. While mixed models can be estimated by ANOVA methods, we instead used restricted maximum likelihood to better deal with unbalanced data. Also, we found that the variances of different transcripts were unequal, and hence took this into account by adding a covariance parameter for each different transcript. Contrasts were constructed to compare the different categories of transcripts, rather than including category as a factor in the model. Mixed model analysis was used for two separate analyses; to investigate i) effects of $\mathrm{Hx}$ vs intact and ii) effects of GHi and GHx2 in the Hx group. Two-tailed analysis were used everywhere, but as the primary objective was to analyze differences between GHx2 and $\mathrm{GHi}$, no further post hoc corrections were used. $P$ values $<0.05$ were considered statistically significant.

\section{Results}

\section{GH exerts systemic effects}

$\mathrm{Hx}$ rats that received two injections of bGH per day (GHx2) gained slightly more weight (21\% difference, $P<0.05$ ) than the GHi group (Table 3). However, even GHx2 did not fully restore weight as compared with the growth of matched intact rats.

\section{$\mathrm{GH}$ administration elicits a robust response in $\mathrm{Hbb}$ expression but modest responses for other transcripts in both the hippocampus and cortex}

As GH administration causes secondary feedback loops in intact rats, we chose to study $\mathrm{Hx}$ rats treated with GHi or GHx2. As Hx almost depletes endogenous circulating GH as compared with intact rats, the effect of GH would be reflected also when comparing expression levels in intact and untreated $\mathrm{Hx}$ rats. However, Hx per se only affected a few transcripts, namely the Igfr $1(-12 \%$, cortex), $H b b(-86.9 \%$, hippocampus and $-79.9 \%$,

Published by Bioscientifica Ltd 
parietal cortex), and the $G f a p(+46.1 \%$, hippocampus) to a statistically significant degree (Table 4 ).

Although, the study was aimed at investigating the differences between GHi and GHx2, we also studied the effects of bGH compared with Hx. Overall, bGH induced changes in transcript abundance in accordance with previous reports (Supplementary Table 1), but in many cases the effects were relatively small and sometimes not statistically significant (Table 4). Furthermore, in the cases where Hx caused a significant change as compared with intact animals, there were two phenomena present. First, with respect to Gfap in the hippocampus, GHx2 increased levels further beyond intact levels (Table 4). Second, in the case of $\mathrm{Hbb}$, both GHi and GHx2, GHx2 somewhat more, partially restored levels to those of intact animals in both regions of brain (Table 4 ).

With regard to the primary hypothesis of differential responses to the different types of $\mathrm{GH}$ administration, only three specific transcripts ( $G h r, C x 43$, and $H b b$ ) exhibited statistically significant differences in the cortex (Table 4). In all three cases, GHx2 gave a higher expression level than GHi.

\section{General effects in the cortex}

Mixed model analysis of all transcripts in the cortex showed a $36.6 \%$ decrease from intact to $\mathrm{Hx}(P<0.001)$. Also, GHx2 increased the expression of all transcripts significantly more compared with GHi (21.5\% higher, $P<0.001)$, and only GHx2 was significantly higher than Hx $(13.2 \%, P=0.001)$. Furthermore, for the specific categories of transcripts, the neuron-related transcripts exhibited a significant difference between the $\mathrm{Hx}$ vs $\mathrm{GHi}$ groups ( $-16 \%$, Fig. 1a) and in the GH-related group there was a significant difference between GHi vs GHx2 (22\%, Fig. 1a). In both cases, GHi showed a negative response as compared with $\mathrm{Hx}$ vs $\mathrm{GHx} 2$. However, the glia-related transcripts were not significantly affected by the mode of GH administration (Fig. 1a).

\section{General effects in the hippocampus}

Mixed model analysis of all transcripts showed a $48.2 \%$ decrease from intact to $\mathrm{Hx}(P<0.001)$, mainly due to the decrease in $H b b$. Furthermore, analysis of all transcripts showed that GHx2 did not increase expression significantly when compared with GHi (9.7\% higher, $P=0.093)$. However, both GHx2 (29.7\%, $P<0.001)$ and GHi $(18.2 \%, P=0.01)$ groups had levels that were significantly higher than animals of the Hx group. With regard
Table 4 The relative mean values for each transcript in each of the treatment groups. Each group value is relative to the intact groups $=100$ for each transcript

\begin{tabular}{|c|c|c|c|}
\hline Transcript & Group & Hippocampus & Cortex \\
\hline \multirow[t]{4}{*}{ Ghr } & Intact & $100.0(83.8-116.2)$ & $100.0(92.4-107.6)$ \\
\hline & $\mathrm{Hx}$ & $90.7(87.5-94.0)$ & $87.9(83.4-92.4)$ \\
\hline & $\mathrm{GHi}$ & $85.4(73.6-97.3)$ & $67.9(59.9-76.0) *$ \\
\hline & $\mathrm{GH} \times 2$ & $101.7(88.2-115.2)$ & $92.5(69.5-115.5)^{\dagger}$ \\
\hline \multirow[t]{4}{*}{$\lg f 1$} & Intact & $100.0(57.9-142.1)$ & $100.0(48.9-151.1)$ \\
\hline & $\mathrm{Hx}$ & $81.3(77.7-84.9)$ & $73.2(69.6-76.7)$ \\
\hline & $\mathrm{GHi}$ & $95.8(78.1-113.4)$ & $66.8(62.2-71.3)$ \\
\hline & $\mathrm{GH} \times 2$ & $98.7(87.0-110.5) *$ & 95.7 (57.7-133.7) \\
\hline \multirow[t]{4}{*}{ Igflr } & Intact & $100.0(76.8-123.2)$ & $100.0(95.3-104.7)$ \\
\hline & $\mathrm{Hx}$ & $98.5(96.0-101.1)$ & $88.0(81.4-94.7)^{\ddagger}$ \\
\hline & $\mathrm{GHi}$ & 95.6 (86.7-104.5) & 75.7 (70.7-80.7) \\
\hline & $\mathrm{GH} \times 2$ & 95.7 (87.7-103.7) & 83.4 (72.4-94.3) \\
\hline \multirow[t]{4}{*}{ Esr1 } & Intact & $100.0(39.8-160.2)$ & $100.0(55.2-144.8)$ \\
\hline & $\mathrm{Hx}$ & $81.9(57.1-106.7)$ & $110.5(96.7-124.4)$ \\
\hline & $\mathrm{GHi}$ & $96.3(65.9-126.6)$ & $88.6(77.7-99.4)$ \\
\hline & $\mathrm{GH} \times 2$ & $90.8(65.3-116.3)$ & $88.1(56.2-119.9)$ \\
\hline \multirow[t]{4}{*}{ Cnp } & Intact & $100.0(75.2-124.8)$ & $100.0(77.4-122.6)$ \\
\hline & $\mathrm{Hx}$ & $104.9(96.9-112.9)$ & $98.7(85.6-111.7)$ \\
\hline & $\mathrm{GHi}$ & $108.1(96.5-119.7)$ & $86.9(73.8-99.9)$ \\
\hline & $\mathrm{GH} \times 2$ & $129.6(111.9-147.2)$ * & $95.1(81.1-109.1)$ \\
\hline \multirow[t]{4}{*}{ Gjal } & Intact & $100.0(80.2-119.8)$ & $100.0(84.1-115.9)$ \\
\hline & $\mathrm{Hx}$ & $114.8(108.6-120.9)$ & $87.8(80.2-95.4)$ \\
\hline & $\mathrm{GHi}$ & $113.8(101.8-125.7)$ & $73.6(66.0-81.2) *$ \\
\hline & $\mathrm{GH} \times 2$ & $124.5(114.2-134.9)$ & $93.1(80.2-106.0)^{\dagger \dagger}$ \\
\hline \multirow[t]{4}{*}{ Gfap } & Intact & $100.0(78.1-121.9)$ & $100.0(86.4-113.6)$ \\
\hline & $\mathrm{Hx}$ & $146.1(133.3-158.9)^{\ddagger \neq}$ & $97.6(85.0-110.3)$ \\
\hline & $\mathrm{GHi}$ & $160.6(136.2-184.9)$ & $89.0(66.2-111.8)$ \\
\hline & $\mathrm{GH} \times 2$ & $187.3(156.7-218.0)^{* *}$ & $105.5(97.4-113.7)$ \\
\hline \multirow[t]{4}{*}{ Grin2a } & Intact & $100.0(58.7-141.3)$ & $100.0(80.9-119.1)$ \\
\hline & $\mathrm{Hx}$ & $140.6(128.4-152.9)$ & $105.4(99.7-111.1)$ \\
\hline & $\mathrm{GHi}$ & $131.6(120.4-142.8)$ & $89.4(78.6-100.2)$ \\
\hline & $\mathrm{GH} \times 2$ & $142.3(121.6-163.0)$ & 94.7 (82.5-106.9) \\
\hline \multirow[t]{4}{*}{ Psd95 } & Intact & $100.0(81.0-119.0)$ & $100.0(92.3-107.7)$ \\
\hline & $\mathrm{Hx}$ & $101.9(97.6-106.1)$ & $105.7(97.9-113.6)$ \\
\hline & $\mathrm{GHi}$ & $100.2(91.7-108.7)$ & $88.7(77.1-100.4)$ \\
\hline & $\mathrm{GH} \times 2$ & $112.6(103.5-121.7)$ & $96.8(85.4-108.3)$ \\
\hline \multirow[t]{4}{*}{ Gabbr1 } & Intact & $100.0(89.8-110.2)$ & $100.0(91.7-108.3)$ \\
\hline & $\mathrm{Hx}$ & $99.5(94.2-104.8)$ & $99.6(93.8-105.5)$ \\
\hline & $\mathrm{GHi}$ & $104.5(91.9-117.2)$ & $86.1(73.3-99.0)$ \\
\hline & $\mathrm{GH} \times 2$ & $113.5(104.0-123.1)$ & $101.0(91.1-110.8)$ \\
\hline \multirow[t]{4}{*}{ Grial } & Intact & $100.0(70.6-129.4)$ & $100.0(82.5-117.7)$ \\
\hline & $\mathrm{Hx}$ & $118.9(106.9-130.9)$ & $88.3(78.7-98.0)$ \\
\hline & $\mathrm{GHi}$ & $120.1(102.4-137.8)$ & $73.5(70.3-76.7)$ \\
\hline & $\mathrm{GH} \times 2$ & $135.4(111.2-159.5)$ & $86.2(67.5-104.9)$ \\
\hline \multirow[t]{4}{*}{ Oprd1 } & Intact & $100.0(49.5-150.5)$ & $100.0(87.3-112.7)$ \\
\hline & $\mathrm{Hx}$ & $97.7(91.9-103.6)$ & $97.5(90.5-104.5)$ \\
\hline & $\mathrm{GHi}$ & $113.1(95.2-131.0)$ & $80.6(58.4-102.8)$ \\
\hline & $\mathrm{GH} \times 2$ & $93.3(87.3-99.4)^{\dagger}$ & $95.5(85.6-105.5)^{\dagger}$ \\
\hline \multirow[t]{4}{*}{$H b b$} & Intact & $100.0(61.4-138.6)$ & $100.0(74.4-125.6)$ \\
\hline & $\mathrm{Hx}$ & $13.1(10.4-15.8)^{\ddagger \neq}$ & $20.1(16.1-24.0)^{\neq \neq \neq}$ \\
\hline & $\mathrm{GHi}$ & $37.2(30.6-43.9)^{* *}$ & $38.6(25.2-52.1)^{* *}$ \\
\hline & $\mathrm{GH} \times 2$ & $45.8(33.4-58.1)^{* * *}$ & $54.6(48.3-60.9)^{* * *}$ \\
\hline
\end{tabular}

Statistically significant differences as analyzed by mixed model analysis ('Materials and methods') are shown with $* P<0.05, * * P<0.01$ and *** $P<0.001$ for $\mathrm{Hx}$ vs GHi or $\mathrm{GH} 2,+P<0.05,+\dagger P<0.01$ and $+\dagger+P<0.001$ for $\mathrm{GHi}$ vs $\mathrm{GHx} 2, \ddagger P<0.05, \ddagger \ddagger P<0.01$ and $\ddagger \ddagger \ddagger P<0.001)$ for $\mathrm{Hx}$ vs intact, respectively. Variation is given as $95 \%$ Cls. http://joe.endocrinology-journals.org DOI: 10.1530/JOE-14-0223
() 2014 Society for Endocrinology Printed in Great Britain 


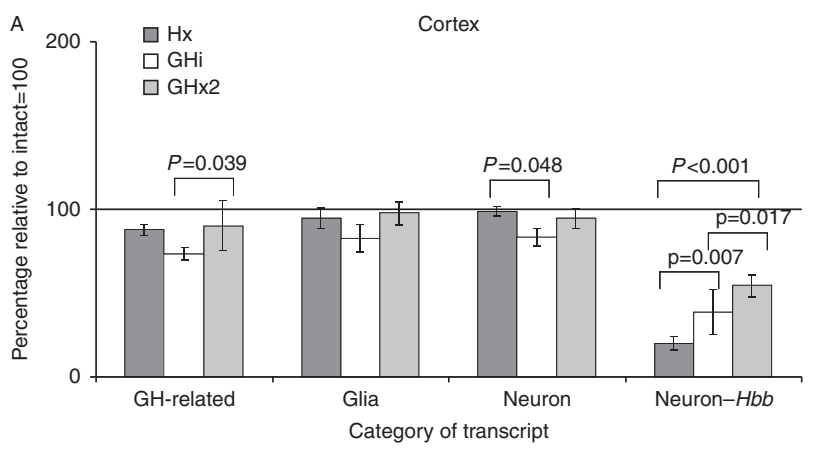

B

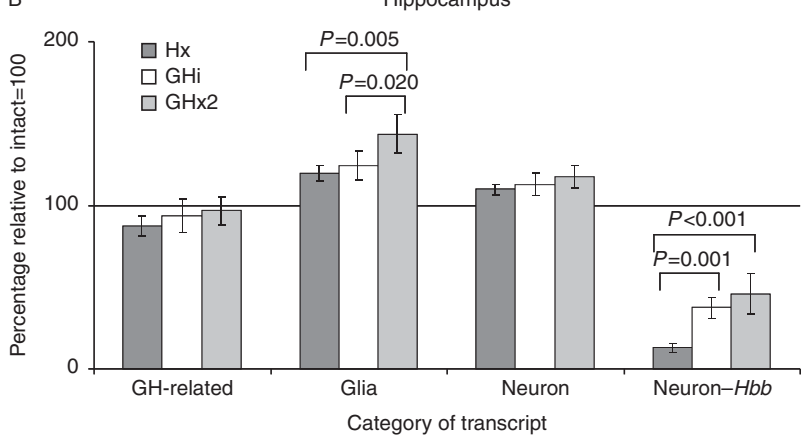

Figure 1

Levels of categories of transcripts in male cortex (a) and hippocampus (b) as analysed by qPCR. Comparisons are made with mixed model analysis. $H b b$ was kept as a separate entity in the analysis due to a unique robust response to GH (see 'Materials and methods'). Intact levels $=100 \%$. Data are presented as mean $\pm 95 \% \mathrm{Cls}$.

to categories of transcript, in the group of glia-related transcripts, there were significant differences observed when comparing Hx vs GHx2 and GHi vs GHx2 (Fig. 1b), with a higher expression in the GHx 2 treatment group. The neuron-related and GH-related transcripts were not significantly affected by any type of GH administration (Fig. 1b).

\section{Discussion}

Our study shows for the first time, to our knowledge, the effects of two types of administration of bGH in the hippocampus and cortex of male rat brains. Bovine $\mathrm{GH}$ administration caused a robust 1.8- to 3.6-fold response from $\mathrm{Hbb}$ to both types of bGH treatment in both the hippocampus and cortex. For $H b b$, the treatment response was higher for GHx2 than GHi (statistically significantly for cortex, and as a trend for the hippocampus). For the other transcripts, the effects of GH treatment were weaker. Furthermore, the mixed model analysis of all transcripts showed a higher expression in the cortex for $\mathrm{GH} 2$ than for GHi, and a trend towards a difference in the hippocampus. In the cortex, the difference between GHi and GHx2 was mainly due to the suppression of transcripts in the GHi group with respect to Hx levels. However, in the hippocampus, both GHi and GHx2 increased expression, GHx2 more than GHi. With regard to different categories of transcripts, there were statistically significant differences between GHi and GHx2 for the GH-related transcripts in the cortex and for the glia-related transcripts in the hippocampus. With respect to restoration toward intact levels, only GH treatment with respect to $H b b$ showed the typical restoration pattern, albeit incomplete. In the hippocampus, GH treatment did not restore levels to those recorded in intact animals for glia-related transcripts, but rather increased the effect of $\mathrm{Hx}$.

The study confirms that GH affects transcripts in the hippocampus and in the cortex (for comparison, see Supplementary Table 1). However, the results also show that GH does not necessarily affect a previously known transcript to a statistically significant degree in the same way in both regions of the brain as compared with previous investigations. It should be pointed out that some of the previous investigations were performed only in female rats, which may affect responses and comparisons. Although primary statistical analysis for each of the transcripts revealed only three cases of significant differences between GHi and GHx2, namely for Ghr, $C x 43$, and $H b b$ in cortex (Table 4), the mixed model analysis revealed significant differences between GHi and GHx2 with regard to several categories of transcript and general effects on all transcripts. Thus, our experiments show that there are definite but usually rather small differences (except for $H b b$ ) in effect between different modes of administration of GH. For aspects regarding the plasticity of $H b b$, possible explanations for the mode of administration of GH and sexually dimorphic differences are discussed in more detail below.

\section{Effects of GH administration with respect to plasticity and neuron-Hbb neuroprotection}

GHi and GHx2 both increase $H b b$ approximately threefold, which is in contrast to the other presently investigated transcripts with lower responses. $H b b$ also had an expression pattern with a much higher response to bGH than the rest of the neuron-related group (Fig. 1b), which is the reason why we chose to separate the display of $H b b$.

In our previous studies, we have shown that $H b b$ is robustly regulated by $\mathrm{GH}$ in female rats (Walser et al. 2012). Although endogenous neuronal (non-erythrocyte) hemoglobin has been found in neurons of rodents and human brain, its function is still not fully clear (Richter et al. 2009, He et al. 2010). However, it has been shown that

Published by Bioscientifica Ltd 
in vitro ischemic preconditioning to hypoxia increased neuronal $H b b$ expression in the penumbral zone after focal brain ischemia (He et al. 2009), indicating an active role for neuronal $\mathrm{Hbb}$ in promoting neuroprotection. Also, Yan et al. (2011) found increased transcription of Alox15, $\mathrm{Hba-a2}$, and $\alpha$ - and $\beta$-globins in response to GH replacement and they indicate that this may imply a mechanism by which IGF1 regulates vascular structure and function through a decrease in oxidative stress in the brain as well as vasculature and that these effects may possibly be mediated by $\mathrm{Hb}$ and globins. Therefore, the response to GH by $\mathrm{Hbb}$ and the differences between $\mathrm{GHi}$ and $\mathrm{GHx} 2$ may have relevance for a neuroprotective action of GH. With regard to our results, GHx2 could thus be more effective in inducing a neuroprotective response in the brain than GHi.

\section{Does an effect of GHx2 administration resemble the male-like endogenous GH secretion in the brain?}

There were some differences in the response to the two different administration paradigms with a higher effect of GHx2 than GHi. Peripherally, this was reflected in an expected higher weight gain of $\mathrm{GHx} 2$ as compared with GHi (Table 3). Although $\mathrm{Hbb}$ showed the greatest difference between $\mathrm{GHx} 2$ and $\mathrm{GHi}$, there were also some significant differences in the specific categories of transcripts. This would be consistent with a type of administration (GHx2) more like the natural GH secretion pattern in males being more optimal in eliciting a response. In the cortex, there was a significant difference between GHx2 and GHi in the GH-related group (Fig. 1a), probably due to an actual suppression of response after GHi compared with GHx2, although the difference between GHi and Hx was not statistically significant. This would also be consistent with a type of administration (ZGHi) resembling the natural GH secretion pattern in females could even have a negative effect with respect to eliciting a response in the male cortex. A contributing factor to this general negative pattern may be that GHi downregulated the Ghr in the cortex (Table 4).

The relatively modest difference between types of administration contrasts with previous reports on systemic responses to different types of GH administration. According to Jansson et al. (1982), a more male-like administration frequency of $\mathrm{GH}$ is more favorable for body weight and optimum growth in Hx male rats given replacement therapy. Specifically, in male rats, injections of GH $\times 2$ increase body weight as compared with $\mathrm{GH} \times 1$ by an additional approximately 39\%, after 8 days.
In analogy, longitudinal bone growth was increased by $15 \%(\mathrm{GH} \times 2)$ as compared with $\mathrm{GH} \times 1$ during the $\mathrm{bGH}$ treatment. Interestingly, $\mathrm{GH} \times 8$ abolished growth almost completely. This difference in optimum growth may be explained by refractoriness in the tissue to a new GH burst too soon after the previous one (Jansson et al. 1985). In agreement also Isgaard et al. (1988) demonstrated that pulsatile treatment induces $I g f 1$ more effectively than continuous $\mathrm{GH}$ in skeletal muscle and rib growth plate. In humans, the type of $\mathrm{GH}$ administration has been less studied, but Jaffe et al. (2002) have examined how sexspecific GH administration patterns could explain different biological responses. However, the study did not present sex-specific results, and therefore direct comparison to our study of male rats cannot be made. Although chosen to cause a rather robust difference in peripheral growth, a weakness of our study is that the two administration paradigms did not cause more than about $25 \%$ difference in peripheral growth. It is possible that with differences of $40 \%$ (Jansson et al. 1982) we might have had more robust differences in brain plasticity as well. However, we believe that the overall pattern of responses would have been similar.

\section{How peripheral pulsatility of GH may be affected by the BBB}

Another aspect on the relatively modest effects of type of GH administration in the brain is that we cannot exclude the possibility that peripheral pulsatility may not be completely transferred to the brain. The first reason for this is that there is a barrier to GH reaching the brain, e.g. the BBB. Although it is now accepted that GH does cross the BBB (Lopez-Fernandez et al. 1996, Ye et al. 1997) at a limited rate (Pan et al. 2005), it is clear that a pulsatile effect of GH injections may be attenuated by a limited and delayed passage of GH. Secondly the effect of GH in the brain may be delayed due to peripheral GH stimulation of local IGF1 expression within the brain (Ye et al. 1997). Thirdly, some of the effects of GH on the brain are probably mediated by peripheral circulating IGF1 (for review, see Åberg et al. (2006)). As circulating IGF1 levels are much more even and regulated by the cumulative effect of GH stimulation over 1-2 days (Bielohuby et al. 2011), the pulsatility of GH injections may be partially attenuated. Specifically, it appears that there are two major transport systems of IGF1 across the BBB. The first is the classical endocytic receptor megalin/LDL receptor-related protein 1 (LRP1) found throughout the capillaries of the brain, through which IGF1 is taken up and transported to IGF1 receptors,

Published by Bioscientifica Ltd. 
that may be modulated by neuronal activity (Nishijima et al. 2010). The second pathway is via a related receptor called endocytic receptor megalin/LRP2 in the choroid plexus (Carro et al. 2005) Altogether there is a possibility that pulsatility of $\mathrm{GH}$ in the circulation is not a priori transferred to the brain, rather it is mediated by cumulative effects in the periphery of which circulating IGF1 is the most important mediator. There is, however, one important exception, and that is if $\mathrm{GH}$ was to be administered when the BBB is malfunctioning due to various injuries and diseases. Therefore, pulsatile vs even GH administration should be carefully investigated if given to promote neuroprotective actions after, for example, HI strokes.

\section{Summary}

This is the first study, to our knowledge, to investigate differences between different modes of GH administration in two important regions of the brain. Both types of administration elicited robust responses from $\mathrm{Hbb}, \mathrm{GHx} 2$ more efficiently than GHi. Whereas the effects of $\mathrm{GH}$ on other transcripts were smaller, the mixed model analysis still showed that the administration of GH as a twice-daily injection was more effective in increasing or restoring transcript levels in the hippocampus and cortex. Altogether, we have shown that different types of $\mathrm{GH}$ administration have an effect on the brain, but the relative differences of the effect are not large, except in the case of $H b b$. This, in turn, may have consequences for neuroprotective actions of $\mathrm{GH}$, if used in relation to injuries of the brain. For other purposes, GH could probably be given by the most convenient method of administration.

\section{Supplementary data}

This is linked to the online version of the paper at http://dx.doi.org/10.1530/ JOE-14-0223.

\section{Declaration of interest}

Except for $\mathrm{J} \mathrm{O}$, who is employee at AstraZeneca R\&D, all other authors declare that there is no conflict of interest that could be perceived as prejudicing the impartiality of the research reported.

\section{Funding}

This study was supported by grants from the Faculty of Medicine of the University of Göteborg (ALF-GBG 74640), the Swedish Society of Medicine, the Göteborg Medical Society, and the Novo Nordisk Foundation.

\section{Author contribution statement}

The authors have made the following declarations about their contributions: M W performed, analyzed, and wrote the study. L S analyzed the study (statistically). J O planned, designed, performed, and wrote the study. M A I A performed and wrote the study. J S wrote the study. N D A planned, designed, performed, analyzed, and wrote the study. J I planned, designed, performed, analyzed, and wrote the study.

\section{References}

Åberg ND, Carlsson B, Rosengren L, Oscarsson J, Isaksson OG, Ronnback L \& Eriksson PS 2000 Growth hormone increases connexin-43 expression in the cerebral cortex and hypothalamus. Endocrinology 141 3879-3886. (doi:10.1210/endo.141.10.77310)

Åberg ND, Brywe KG \& Isgaard J 2006 Aspects of growth hormone and insulin-like growth factor-I related to neuroprotection, regeneration, and functional plasticity in the adult brain. Scientific World Journal 6 53-80. (doi:10.1100/tsw.2006.22)

Åberg ND, Johansson UE, Åberg MA, Hellstrom NA, Lind J, Bull C, Isgaard J, Anderson MF, Oscarsson J \& Eriksson PS 2007 Peripheral infusion of insulin-like growth factor-I increases the number of newborn oligodendrocytes in the cerebral cortex of adult hypophysectomized rats. Endocrinology 148 3765-3772. (doi:10.1210/ en.2006-1556)

Åberg ND, Johansson I, Åberg MA, Lind J, Johansson UE, Cooper-Kuhn CM, Kuhn HG \& Isgaard J 2009 Peripheral administration of GH induces cell proliferation in the brain of adult hypophysectomized rats. Journal of Endocrinology 201 141-150. (doi:10.1677/JOE-08-0495)

Åberg ND, Lind J, Isgaard J \& Kuhn HG 2010 Peripheral growth hormone induces cell proliferation in the intact adult rat brain. Growth Hormone \& IGF Research 20 264-269. (doi:10.1016/j.ghir.2009.12.003)

Adams MM, Elizabeth Forbes M, Constance Linville M, Riddle DR, Sonntag WE \& Brunso-Bechtold JK 2009 Stability of local brain levels of insulin-like growth factor-I in two well-characterized models of decreased plasma IGF-I. Growth Factors 27 181-188. (doi:10.1080/ 08977190902863639)

Andersen CL, Jensen JL \& Orntoft TF 2004 Normalization of real-time quantitative reverse transcription-PCR data: a model-based variance estimation approach to identify genes suited for normalization, applied to bladder and colon cancer data sets. Cancer Research 64 5245-5250. (doi:10.1158/0008-5472.CAN-04-0496)

Armstrong CS, Wuarin L \& Ishii DN 2000 Uptake of circulating insulin-like growth factor-I into the cerebrospinal fluid of normal and diabetic rats and normalization of IGF-II mRNA content in diabetic rat brain. Journal of Neuroscience Research 59 649-660. (doi:10.1002/(SICI)10974547(20000301)59:5 < 649::AID-JNR8>3.0.CO;2-W)

Bengtsson BA, Eden S, Lonn L, Kvist H, Stokland A, Lindstedt G, Bosaeus I, Tolli J, Sjostrom L \& Isaksson OG 1993 Treatment of adults with growth hormone $(\mathrm{GH})$ deficiency with recombinant human $\mathrm{GH}$. Journal of Clinical Endocrinology and Metabolism 76 309-317. (doi:10.1210/jcem. 76.2.8432773)

Bettler B, Kaupmann K, Mosbacher J \& Gassmann M 2004 Molecular structure and physiological functions of $\mathrm{GABA}_{\mathrm{B}}$ receptors. Physiological Reviews 84 835-867. (doi:10.1152/physrev.00036.2003)

Bielohuby M, Schaab M, Kummann M, Sawitzky M, Gebhardt R, Binder G, Frystyk J, Bjerre M, Hoeflich A, Kratzsch J et al. 2011 Serum IGF-I is not a reliable pharmacodynamic marker of exogenous growth hormone activity in mice. Endocrinology 152 4764-4776. (doi:10.1210/ en.2011-1432)

Bonefeld BE, Elfving B \& Wegener G 2008 Reference genes for normalization: a study of rat brain tissue. Synapse 62 302-309. (doi:10.1002/ syn.20496)

Carro E, Spuch C, Trejo JL, Antequera D \& Torres-Aleman I 2005 Choroid plexus megalin is involved in neuroprotection by serum insulin-like growth factor I. Journal of Neuroscience 25 10884-10893. (doi:10.1523/ JNEUROSCI.2909-05.2005) 
Chebib M \& Johnston GA 1999 The 'ABC' of GABA receptors: a brief review. Clinical and Experimental Pharmacology \& Physiology 26 937-940. (doi:10.1046/j.1440-1681.1999.03151.x)

Craig AM, Blackstone CD, Huganir RL \& Banker G 1993 The distribution of glutamate receptors in cultured rat hippocampal neurons: postsynaptic clustering of AMPA-selective subunits. Neuron 10 1055-1068. (doi:10.1016/0896-6273(93)90054-U)

D'Ercole AJ, Ye P, Calikoglu AS \& Gutierrez-Ospina G 1996 The role of the insulin-like growth factors in the central nervous system. Molecular Neurobiology 13 227-255. (doi:10.1007/BF02740625)

Eden S 1979 Age- and sex-related differences in episodic growth hormone secretion in the rat. Endocrinology 105 555-560. (doi:10.1210/ endo-105-2-555)

Falleti MG, Maruff P, Burman P \& Harris A 2006 The effects of growth hormone $(\mathrm{GH})$ deficiency and $\mathrm{GH}$ replacement on cognitive performance in adults: a meta-analysis of the current literature. Psychoneuroendocrinology 31 681-691. (doi:10.1016/j.psyneuen.2006. 01.005)

Folli F, Ghidella S, Bonfanti L, Kahn CR \& Merighi A 1996 The early intracellular signaling pathway for the insulin/insulin-like growth factor receptor family in the mammalian central nervous system. Molecular Neurobiology 13 155-183. (doi:10.1007/BF02740639)

Guan J, Miller OT, Waugh KM, McCarthy DC \& Gluckman PD 2001 Insulin-like growth factor-1 improves somatosensory function and reduces the extent of cortical infarction and ongoing neuronal loss after hypoxia-ischemia in rats. Neuroscience 105 299-306. (doi:10.1016/ S0306-4522(01)00145-2)

Guan J, Bennet L, Gluckman PD \& Gunn AJ 2003 Insulin-like growth factor-1 and post-ischemic brain injury. Progress in Neurobiology 70 443-462. (doi:10.1016/j.pneurobio.2003.08.002)

Gustafson K, Hagberg H, Bengtsson BA, Brantsing C \& Isgaard J 1999 Possible protective role of growth hormone in hypoxia-ischemia in neonatal rats. Pediatric Research 45 318-323. (doi:10.1203/00006450199903000-00005)

He Y, Hua Y, Liu W, Hu H, Keep RF \& Xi G 2009 Effects of cerebral ischemia on neuronal hemoglobin. Journal of Cerebral Blood Flow and Metabolism 29 596-605. (doi:10.1038/jcbfm.2008.145)

He Y, Hua Y, Lee JY, Liu W, Keep RF, Wang MM \& Xi G 2010 Brain $\alpha$ - and $\beta$-globin expression after intracerebral hemorrhage. Translational Stroke Research 1 48-56. (doi:10.1007/s12975-009-0004-x)

Isgaard J, Carlsson L, Isaksson OG \& Jansson JO 1988 Pulsatile intravenous growth hormone $(\mathrm{GH})$ infusion to hypophysectomized rats increases insulin-like growth factor I messenger ribonucleic acid in skeletal tissues more effectively than continuous GH infusion. Endocrinology 123 2605-2610. (doi:10.1210/endo-123-6-2605)

Iwata M, Inoue S, Kawaguchi M, Nakamura M, Konishi N \& Furuya H 2007 Effects of $\delta$-opioid receptor stimulation and inhibition on hippocampal survival in a rat model of forebrain ischaemia. British Journal of Anaesthesia 99 538-546. (doi:10.1093/bja/aem220)

Jaffe CA, Turgeon DK, Lown K, Demott-Friberg R \& Watkins PB 2002 Growth hormone secretion pattern is an independent regulator of growth hormone actions in humans. American Journal of Physiology. Endocrinology and Metabolism 283 E1008-E1015. (doi:10.1152/ajpendo. 00513.2001)

Jansson JO, Albertsson-Wikland K, Eden S, Thorngren KG \& Isaksson 01982 Circumstantial evidence for a role of the secretory pattern of growth hormone in control of body growth. Acta Endocrinologica 99 24-30. (doi:10.1530/acta.0.0990024)

Jansson JO, Eden S \& Isaksson O 1985 Sexual dimorphism in the control of growth hormone secretion. Endocrine Reviews 6 128-150. (doi:10.1210/ edrv-6-2-128)

Kooijman R, Sarre S, Michotte Y \& Keyser JD 2009 Insulin-like growth factor I: a potential neuroprotective compound for the treatment of acute ischemic stroke? Stroke 40 e83-e88. (doi:10.1161/STROKEAHA 108.528356)
Le Greves M, Steensland P, Le Greves P \& Nyberg F 2002 Growth hormone induces age-dependent alteration in the expression of hippocampal growth hormone receptor and $N$-methyl-D-aspartate receptor subunits gene transcripts in male rats. PNAS 99 7119-7123. (doi:10.1073/pnas. 092135399)

Le Greves M, Zhou Q, Berg M, Le Greves P, Fholenhag K, Meyerson B \& Nyberg F 2006 Growth hormone replacement in hypophysectomized rats affects spatial performance and hippocampal levels of NMDA receptor subunit and PSD-95 gene transcript levels. Experimental Brain Research 173 267-273. (doi:10.1007/s00221-006-0438-2)

Lin S, Fan LW, Pang Y, Rhodes PG, Mitchell HJ \& Cai Z 2005 IGF-1 protects oligodendrocyte progenitor cells and improves neurological functions following cerebral hypoxia-ischemia in the neonatal rat. Brain Research 1063 15-26. (doi:10.1016/j.brainres.2005.09.042)

Lobie PE, Garcia-Aragon J, Lincoln DT, Barnard R, Wilcox JN \& Waters MJ 1993 Localization and ontogeny of growth hormone receptor gene expression in the central nervous system. Brain Research. Developmental Brain Research 74 225-233. (doi:10.1016/0165-3806(93)90008-X)

Lopez-Fernandez J, Sanchez-Franco F, Velasco B, Tolon RM, Pazos F \& Cacicedo L 1996 Growth hormone induces somatostatin and insulinlike growth factor I gene expression in the cerebral hemispheres of aging rats. Endocrinology 137 4384-4391. (doi:10.1210/endo.137.10. 8828499)

Maiter D, Walker JL, Adam E, Moatsstaats B, Mulumba N, Ketelslegers JM \& Underwood LE 1992 Differential regulation by growth hormone (GH) of insulin-like growth factor I and GH receptor/binding protein gene expression in rat liver. Endocrinology 130 3257-3264. (doi:10.1210/ endo.130.6.1375898)

Martin LJ, Blackstone CD, Levey AI, Huganir RL \& Price DL 1993 AMPA glutamate receptor subunits are differentially distributed in rat brain. Neuroscience 53 327-358. (doi:10.1016/0306-4522(93)90199-P)

McGauley GA 1989 Quality of life assessment before and after growth hormone treatment in adults with growth hormone deficiency. Acta Paediatrica Scandinavica. Supplement 356 70-72 (discussion 73-74). (doi:10.1111/j.1651-2227.1989.tb11249.x)

Nishijima T, Piriz J, Duflot S, Fernandez AM, Gaitan G, Gomez-Pinedo U, Verdugo JM, Leroy F, Soya H, Nuñez A et al. 2010 Neuronal activity drives localized blood-brain-barrier transport of serum insulin-like growth factor-I into the CNS. Neuron 67 834-846. (doi:10.1016/ j.neuron.2010.08.007)

Ohyagi Y, Yamada T \& Goto I 1994 Hemoglobin as a novel protein developmentally regulated in neurons. Brain Research 635 323-327. (doi:10.1016/0006-8993(94)91455-9)

Oscarsson J, Ottosson M, Vikman-Adolfsson K, Frick F, Enerback S, Lithell H \& Eden S 1999 GH but not IGF-I or insulin increases lipoprotein lipase activity in muscle tissues of hypophysectomised rats. Journal of Endocrinology 160 247-255. (doi:10.1677/joe.0.1600247)

Pan W, Yu Y, Cain CM, Nyberg F, Couraud PO \& Kastin AJ 2005 Permeation of growth hormone across the blood-brain barrier. Endocrinology 146 4898-4904. (doi:10.1210/en.2005-0587)

Pathipati P, Surus A, Williams CE \& Scheepens A 2009 Delayed and chronic treatment with growth hormone after endothelin-induced stroke in the adult rat. Behavioural Brain Research 204 93-101. (doi:10.1016/j.bbr. 2009.05.023)

Pekny M, Leveen P, Pekna M, Eliasson C, Berthold CH, Westermark B \& Betsholtz C 1995 Mice lacking glial fibrillary acidic protein display astrocytes devoid of intermediate filaments but develop and reproduce normally. EMBO Journal 14 1590-1598.

Persson AI, Åberg ND, Oscarsson J, Isaksson OG, Ronnback L, Frick F, Sonesson C \& Eriksson PS 2003 Expression of $\delta$ opioid receptor mRNA and protein in the rat cerebral cortex and cerebellum is decreased by growth hormone. Journal of Neuroscience Research 71 496-503. (doi:10.1002/jnr.10515)

Pons S \& Torres-Aleman I 1993 Estradiol modulates insulin-like growth factor I receptors and binding proteins in neurons from the 
hypothalamus. Journal of Neuroendocrinology 5 267-271. (doi:10.1111/ j.1365-2826.1993.tb00482.x)

Richter F, Meurers BH, Zhu C, Medvedeva VP \& Chesselet MF 2009 Neurons express hemoglobin $\alpha$ - and $\beta$-chains in rat and human brains. Journal of Comparative Neurology 515 538-547. (doi:10.1002/cne.22062)

Scheepens A, Sirimanne ES, Breier BH, Clark RG, Gluckman PD \& Williams CE 2001 Growth hormone as a neuronal rescue factor during recovery from CNS injury. Neuroscience 104 677-687. (doi:10.1016/S03064522(01)00109-9)

Schneider-Rivas S, Rivas-Arancibia S, Vazquez-Pereyra F, Vazquez-Sandoval R \& Borgonio-Perez G 1995 Modulation of long-term memory and extinction responses induced by growth hormone (GH) and growth hormone releasing hormone (GHRH) in rats. Life Sciences $\mathbf{5 6}$ PL433-441. (doi:10.1016/0024-3205(95)00171-2)

Thorngren KG \& Hansson LI 1973 Effect of thyroxine and growth hormone on longitudinal bone growth in the hypophysectomized rat. Acta Endocrinologica 74 24-40. (doi:10.1530/acta.0.0740024)

Walser M, Hansen A, Svensson PA, Jernas M, Oscarsson J, Isgaard J \& Åberg ND 2011 Peripheral administration of bovine GH regulates the expression of cerebrocortical $\beta$-globin, GABAB receptor 1 , and the
Lissencephaly-1 protein (LIS-1) in adult hypophysectomized rats. Growth Hormone \& IGF Research 21 16-24. (doi:10.1016/j.ghir.2010. 11.002)

Walser M, Sama MT, Wickelgren R, Aberg MA, Bohlooly YM, Olsson B, Tornell J, Isgaard J \& Åberg ND 2012 Local overexpression of growth hormone and GH/IGF-1 effects in the adult mouse hippocampus. Journal of Endocrinology 215 257-268. (doi:10.1530/JOE-12-0077)

Xu J, Li C, Yin XH \& Zhang GY 2008 Additive neuroprotection of GABA A and GABA B receptor agonists in cerebral ischemic injury via PI-3K/Akt pathway inhibiting the ASK1-JNK cascade. Neuropharmacology $\mathbf{5 4}$ 1029-1040. (doi:10.1016/j.neuropharm.2008.01.014)

Yan H, Mitschelen M, Bixler GV, Brucklacher RM, Farley JA, Han S, Freeman WM \& Sonntag WE 2011 Circulating IGF1 regulates hippocampal IGF1 levels and brain gene expression during adolescence. Journal of Endocrinology 211 27-37. (doi:10.1530/ JOE-11-0200)

Ye P, Umayahara Y, Ritter D, Bunting T, Auman H, Rotwein P \& D'Ercole AJ 1997 Regulation of insulin-like growth factor I (IGF-I) gene expression in brain of transgenic mice expressing an IGF-I-luciferase fusion gene. Endocrinology 138 5466-5475. (doi:10.1210/endo.138.12.5600)

Received in final form 19 May 2014

Accepted 27 May 2014

Accepted Preprint published online 28 May 2014
C 2014 Society for Endocrinology Printed in Great Britain
Published by Bioscientifica Ltd. 